\title{
MODELLING OF TRAILS UP A MOUNTAIN WITH THE LEAST ENERGY EXPENDITURE
}

\author{
Hyounkyun Oh \\ Department of Mathematics
}

\author{
Vanda Johnson \\ Department of Mathematics
}

Sujin Kim

Department of Mathematics

Savannah State University, Savannah, GA, USA

\begin{abstract}
This research explores two major building blocks: development of digital elevation model (DEM) for Stone Mountain in Georgia, and examination of energy expenditure along the existing/newly created trails on the mountain park. The DEM from a topographical information on an old park brochure, is achieved utilizing the 3D numerical bi-cubic spline interpolation method together with regressive outside points from boundary of contours. The evaluation of existing and new park trails from fixed points to the summit of the produced 3D mountain is also achieved through the formula for biomechanical energy expenditure in the human body. Furthermore, we examine Minetti's theory and compare the results of each park trail by observing the graphs of the trail gradient. The resultant data shows that the existing trail is well developed reflecting the Minetti's theory and newly developed trail may be also adopted.
\end{abstract}

Keywords - Digital Elevation Model, Bicubic spline interpolation, Metabolic Energy expenditure

\section{INTRODUCTION}

As an effective teaching and learning methodology, projectbased learning (PBL) has been advocated in much literature in many academic fields over the past decades. To summarize, the positive effects of PBL are described that it deepens students' academic conceptual understandings and encourages them to do critical thinking through its applications (Singer et al. 2012). Such positive effects of PBL are proved in educational levels ranging from K-12 education (Cervantes et al. 2015), (Ergül et al. 2014), (Holmes et al. 2016), (Filcik et al. 2012) through undergraduate courses (Bilgin et al. 2015), (Fini et al. 2018), (Heinricher et al. 2013), (Beier et al. 2019).

As an extensive learning approach of PBL, the summerundergraduate-research-experience (SURE) has been considered to be a higher-impact educational practice for achieving academic excellence and gaining positive attitudes towards future career pursuits. Students' conduct on SURE has revealed an extensive array of professional benefits, such as research skills, and personal benefits, such as independence of intrinsic motivation for learning, the increase of selfconfidence, and more advantage in any career path in (Lopatto 2017), (Sell 2018). Many educators, particularly in the science- technology-engineering-mathematics (STEM) fields believe that the research experience also compels the students' interest in science careers (Singer et al. 2012). Such sequential effects are linked to long-standing heightened performance into graduate degrees (Carpi et al. 2017), (Gilmore et al. 2015), (Robnett et al. 2015).

Based on such information, federal funding agencies including the National Science Foundation (NSF) have supported undergraduate research by sponsoring professional development opportunities across the science and engineering disciplines (Singer et al. 2012).

This article introduces sequential undergraduate research processes with the following factors:

- How situational questions can be analyzed in Mathematics

- How they can be simulated in MATLAB

- How the conclusion is drawn

through a summer-undergraduate-research-training (SURT), which is conducted by an undergraduate student who has just completed the only Calculus in Mathematics and a general Physics course.

Scenario: The story starts with an old park brochure that a

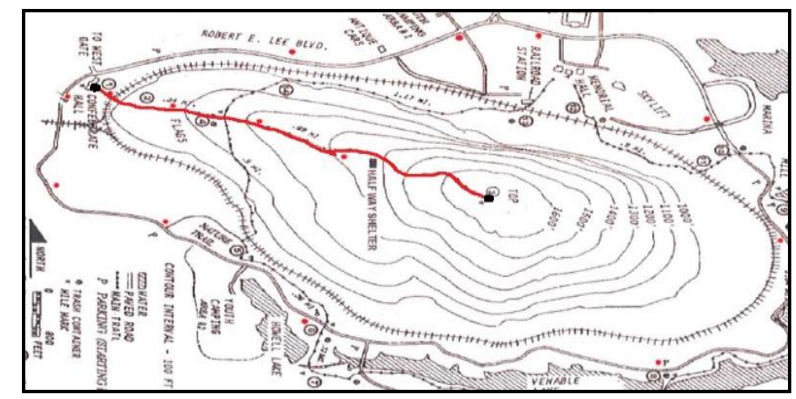

Figure 1. The park brochure of the Stone Mountain

student brought up one day. The brochure is about the exercise activity areas around the Stone Mountain, a unique geological granite mountain forming a round bald of rock rising up south of the Atlanta skyline in Georgia, USA. It also contains a walk trail (shown in the red curve) on several topographical contours as shown in Fig. 1.

The student wondered if the existent trail is the best way up a hill with the least exhaustion and if not, how the best trail 
could be developed only with given information on the brochure. In order to resolve the student's curiosities, we planned to conduct the research in section II by

- searching for the related literature

- building the digital elevation Model of the map

- and calculating the biomechanical energy expenditure of the human body along the trail

Theoretically and empirically we agree that the steeper sections of the trail quickly exhausted our reserves, but the less steep sections did not get up the hill fast enough to make satisfactory progress. Then what is the best way up a hill? Alberto E. Minetti in (Minetti 1995) states when the slope of the route is about 15 degree, the energy required to gain a certain altitude is minimized. In other words, in order to minimize the energetic cost of climbing, hikers should proceed directly up slopes no steeper than 15 degree, and thus on steeper grades they should take zigzag route keeping the climbing angle at 15 degree.

Then how can we develop the best trail up the mountain with the lowest energy expenditure? The answer may be 'it is impossible' because of various reasons including infinitely many possible starting points, infinitely many choice of directions, individually unique metabolic systems, etc. Nevertheless, once a trail is drawn, we could calculate at least the required energy expenditure along the trail.

The rest of the paper is organized with experimentsas follows. Proposed embedding and extraction algorithms are explained in section II. Experimental results are presented in section II. Concluding remarks are given in section III.

\section{PROCESS \& ANALYSIS}

\section{A. Digital Elevation Models (DEM)}

In general, a digital elevation model (DEM) is defined as a digital regularly spaced GRID and a real 3D model which represents the bare ground surface without any objects like plants and buildings. Such DEM can be extensively used to extract the terrain parameters, to render the $3 \mathrm{D}$ visualizations, to design the engineering infrastructure, and so on. In creating these DEMs, the elevation data are obtained through stereo photogrammetry from aerial surveys, block adjustment from optical satellite imagery, interferometry from radar data, topographic maps, inertial surveys, etc. The critical factors for quality of DEM-derived products can include terrain roughness, sampling density (elevation data collection method), grid resolution or pixel size, interpolation algorithm, etc.

The work for developing DEM for the Stone Mountain is done through two steps: application of image processing techniques and utilization of Numerical method.

Image matrix acquisition: First, the park brochure is scanned into an image. See Error! Reference source not found.. Reading the scanned image in MATLAB implies the acquisition of a big matrix of pixel elements in which each pixel contains information of gray intensity. For most images, pixel values are integers that range from 0 (black) to 255 (white). From the scanned image, a topographical contour map can be obtained by erasing the unnecessary information. See Error! Reference source not found. a). Then the elements of black pixel in the matrix are replaced with the corresponding altitudes Error! Reference source not found. b) which produces a 3D matrix. The third components address the altitudes of the mountain. For convenient computational handling the elements of empty altitude are filled with zeros.
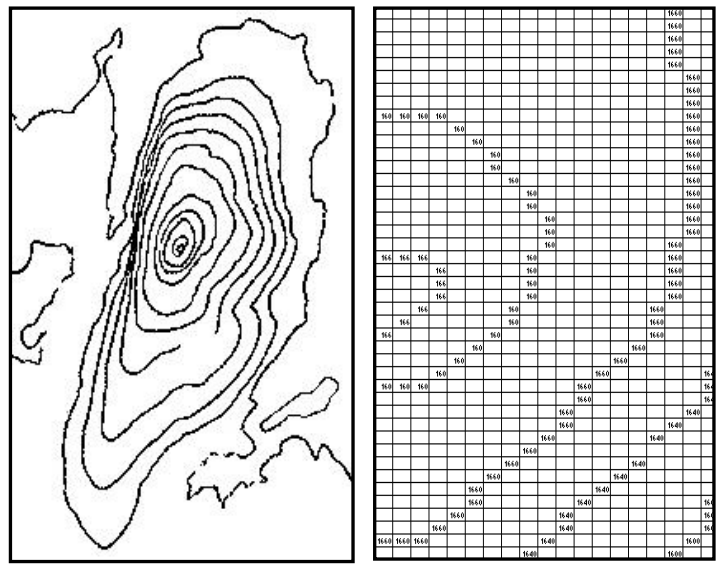

Figure 2. a) Extracted topological map, b) Matrix representation

Scaling and bicubic interpolation: In order to have a right scaled DEM, the scale indicator in the brochure is measured in the pixel (or matrix-element) units, in which 53 pixels corresponds 800 feet. That is, the actual longitude and latitude distances in feet are obtained through multiplying matrixelement unit by 800/53 and are recorded in the first and second component of the 3D matrix. Now the spline interpolation

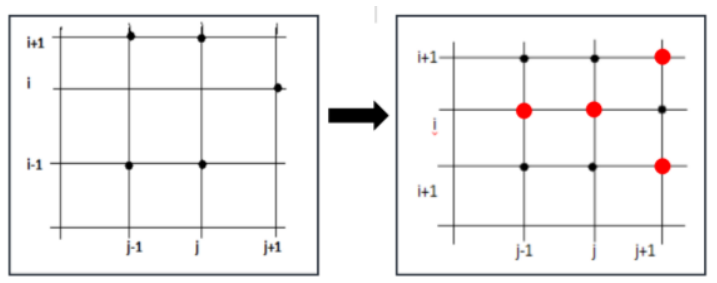

Figure 2. Bicubic interpolation procedure over the topological matrix

technique (Burden at al. 2010) is employed along both rows and columns of the matrix. That is, the bicubic interpolation techniques is implemented. Fig. 3 shows the way to obtain the altitudes through the bicubic interpolation. Outside elements from the boundary contour nodes, if necessary, can be estimated by applying the least square method or the weighted least square method along the rows/columns. 
Surface Curve: The built-in functions 'surf(X,Y,Z)' or 'mesh $(X, Y, Z)$ ' in MATLAB finally create a 3D surface over the newly obtained matrix after scaling as shown in Fig. 4.

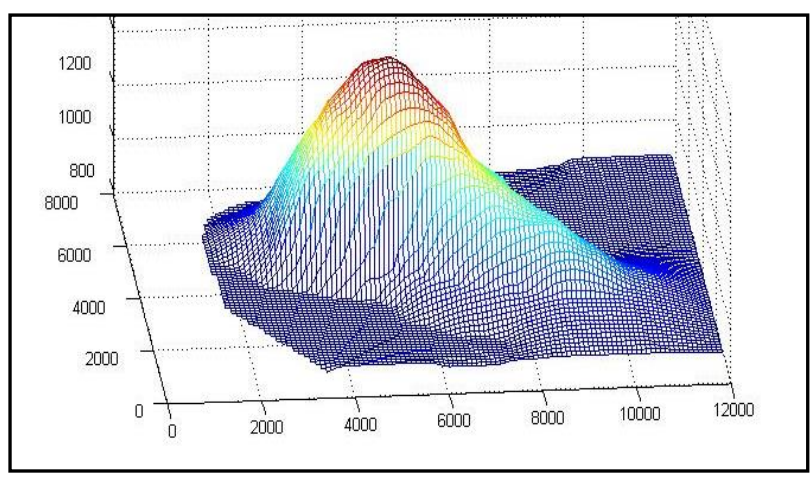

Figure 3. 3D elevation model of the Stone Mountain

\section{B. Arc Length of 3D Surface}

In order to evaluate the park trails in the aspect of energy expenditure, the distance along the path must be calculated first. In mathematics, the length along a curve is defined by

$$
\boldsymbol{s}=\int_{C}|d \ell|=\int_{C} d s
$$

where $d \ell$ is a differential displacement vector along a curve $C$. In the three dimensional rectangular coordinates, if the curve is written

then

$$
\boldsymbol{r}(t)=<x(t), y(t), z(t)>
$$

$$
\begin{aligned}
& \boldsymbol{s}=\int_{a}^{b} \sqrt{x^{\prime 2}(t)+y^{\prime 2}(t)+z^{\prime 2}(t)} d t \\
& =\lim _{|\Delta s| \rightarrow 0} \sum \sqrt{(\Delta x)^{2}+(\Delta y)^{2}+(\Delta z)^{2}} .
\end{aligned}
$$

Thus the arc length s can be approximated as

$$
\boldsymbol{s} \approx \sum_{i=0}^{n} \sqrt{\left(\Delta x_{i}\right)^{2}+\left(\Delta y_{i}\right)^{2}+\left(\Delta z_{i}\right)^{2}} .
$$

\section{Energy Expenditure}

The total energy expenditure for locomotion in humans is described by the rate of metabolic energy in mechanical work done per body mass $(\mathrm{W} / \mathrm{kg})$ which is measured from the net $\mathrm{O}_{2}$ consumption values. Assuming the constant walking speed, the cost also depends on the characteristics of the terrain, including softness/hardness of the ground and surface gradient. Again assuming the consistent material ground, the cost function for walking is approximated with the a polynomial of degree 5 defined by

$$
C_{i}=280.5 i^{5}-58.7 i^{4}-76.8 i^{3}+51.9 i^{2}+19.6 i+2.5
$$

where $i$ is the gradient of hill surface. See the detail in (Minett et al. 2002). Using the coefficients, the total cost of energy $E$ is then approximated in the formula

$$
\mathrm{E}=\sum_{i=0}^{n} C_{i} \sqrt{\left(\Delta x_{i}\right)^{2}+\left(\Delta y_{i}\right)^{2}+\left(\Delta z_{i}\right)^{2}}
$$

where the gradient $i=\tan ^{-1}\left(\frac{\Delta z}{\sqrt{\Delta x^{2}+\Delta y^{2}}}\right)$. Then the total

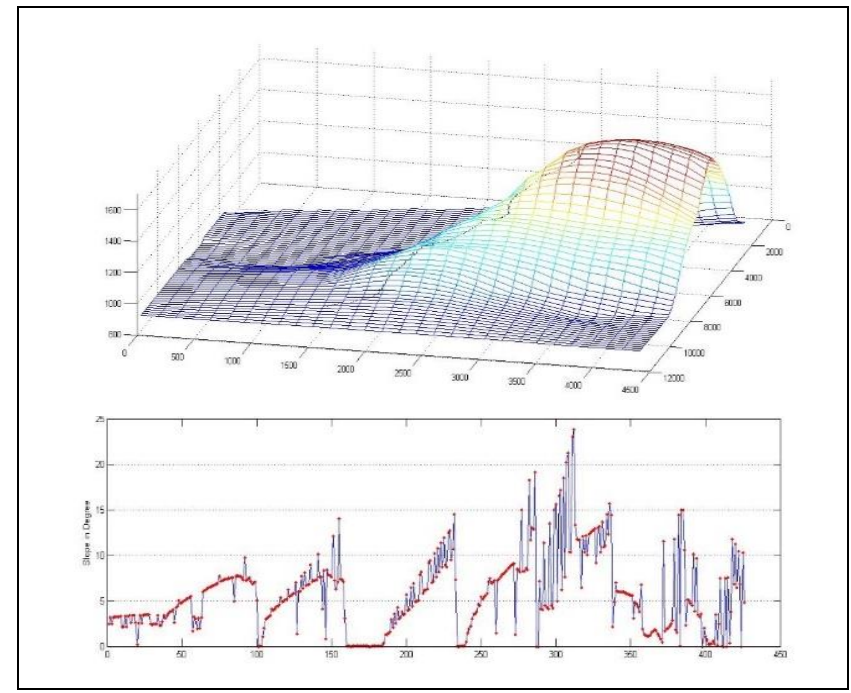

Figure 4. Existent trail and its gradient

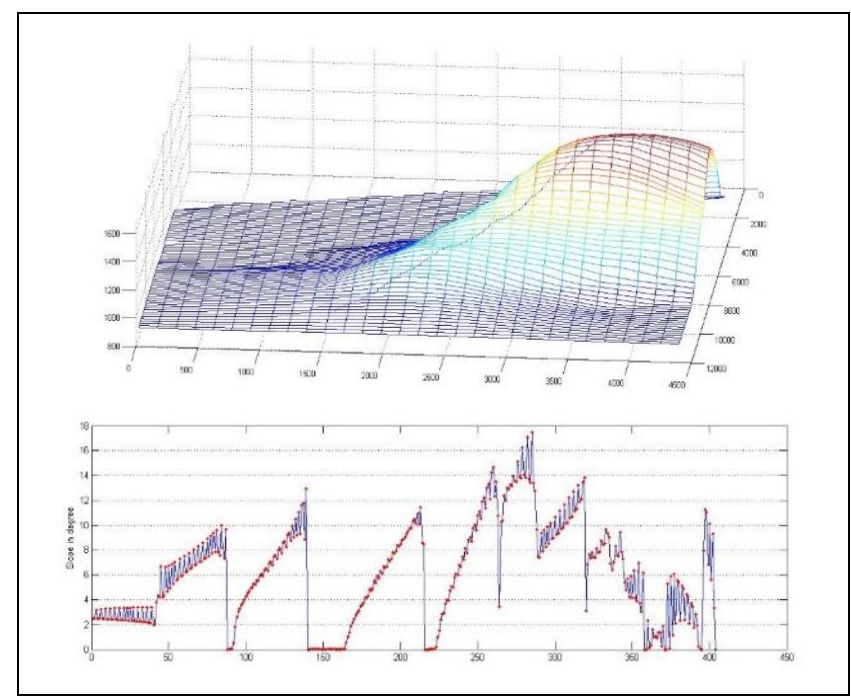

Figure 6. Newly developed trail and its gradient

Energy cost for walking up the old trail in Figure 4 a) is calculated at $5.7072 \mathrm{e}+003 \mathrm{~J} / \mathrm{Kg}$. By looking at the gradient graph in Figure 4 , the middle road is steeper than 15 degree.

\section{Development of new trail}




\section{International Journal of Engineering Applied Sciences and Technology, 2020 \\ Vol. 4, Issue 11, ISSN No. 2455-2143, Pages 434-437 \\ Published Online March 2020 in IJEAST (http://www.ijeast.com)}

By connecting the starting point and the summit of the mountain with a straight line, a new trail is simply developed in theory as shown in Fig. 6. Then the total energy cost is calculated at $5.7072 \mathrm{e}+003 \mathrm{~J} / \mathrm{Kg}$, which is slightly less than one for the old trail. The slope graph of the new trail in Fig. 6 justifies the reason with the less changeable gradient.

\section{CONCLUSION}

Minetti at al. say that the optimal trail up a hill can be found along the less than 15 degree steepness. Despite of this theory, it seems realistically difficult or almost impossible to find the best optimal trail up a mountain with the lowest energy expenditure due to various factors: infinitely many candidate of trails, individually unique metabolic systems, distinctive environment of the mountains, etc. Nevertheless, we are still interested in finding the better trail up a given mountain. And the work for scholastically finding such a route in the mountain can be still valuable and contributed to the various research fields, including creation of $3 \mathrm{D}$ visualized map, virtual analysis of mountain surface, evaluation of existing trails, and their applications.

\section{REFERENCES}

[1] Singer, S. R.; Nielsen, N. R.; and Schweingruber, H.A. (2012), "Discipline-Based Education Research: Understanding and Improving Learning in Undergraduate Science and Engineering", Washington DC: The National Academies Press

[2] Cervantes, B.; Hemmer, L.; and Kouzekanani, K. (2015), "The Impact of Project-Based Learning on Minority Student Achievement: Implications for School Redesign." NCPEA Education Leadership Review of Doctoral Research, 2 (2)

[3] Ergül, N. R.; and Kargin, E. K., (2014), "The effect ff project based learning on students' science success." Procedia - Social and Behavioral Sciences, 136: 537 - 541

[4] Holmes, V.; and Hwang, Y., (2016), "Exploring the effects of project-based learning in secondary mathematics education." The Journal of Educational Research 109 (5): 449-463

[5] Filcik, A.; Bosch, K.; Pederson, S.; and Haugen, N. (2012), "The Effects of Project-Based Learning (PBL) Approach on the Achievement and Efficacy of High School Mathematics Students: A Longitudinal Study Investigating the Effects of the PBL Approach in Mathematics Education." The National Conference On Undergraduate Research (NCUR). Weber State University, Ogden, Utah

[6] Bilgin, I.; Karakuyu, Y.; and Ay, Y. (2015), "The Effects of Project Based Learning on Undergraduate Students' Achievement and Self-Efficacy Beliefs towards Science Teaching." EURASIA Journal of Mathematics, Science \& Technology Education 11 (3): 469-477
[7] Fini, E. H.; Awadallah, F.; Parast, M. M.; and AbuLebdeh, T. (2018), "The impact of project-based learning on improving student learning outcomes of sustainability concepts in transportation engineering courses." European Journal of Engineering Education 43 (3): 473-488

[8] Heinricher, A.; Quinn, P.; Vaz, R. F.; and Rissmiller, K., (2013), "Long-Term Impacts of Project-Based Learning in Science and Engineering." 120th ASEE Annual Conference and Exposition. Atlanta, Georgia, USA

[9] Beier, M. E.; Kim, M. H.; Saterbak, A.; Leautaud, V.; Bishnoi, S.; and Gilberto, J. M. (2019), "The effect of authentic project-based learning on attitudes and career aspirations in STEM." Journal of Research in Science Teaching - Wiley Online Library 56 (1): 3-23

[10] Lopatto, D., (2017), "Undergraduate Research Experiences Support Science Career Decisions and Active Learning ." CBE_Life Sciences Education 6 (4)

[11] Sell, A. J., (2018), "The Impact of Undergraduate Research on Academic Success." Council on Undergraduate Research Quarterly 1: 19-29

[12] Carpi, A.; Ronan, D. M.; Falconer, H. M.; and Lents, N. H. (2017), "Cultivating Minority Scientists: Undergraduate Research Increases Self-Efficacy and Career Ambitions for Underrepresented Students in STEM." Journal of Research in Science Teaching 54 (2): 169-194

[13] Gilmore, J.; Vieyra, M.; Timmerman, B.; Feldon, D.; and Maher, M. (2015), "The Relationship between Undergraduate Research Participation and Subsequent Research Performance of Early Career STEM Graduate Students." Journal of Higher Education 86 (6): 834-863

[14] Robnett, R. D.; Chemers, M. M.; and Zurbriggen, E. L. (2015), "Longitudinal associations among undergraduates' research experience, self-efficacy, and identity." Journal of Research in Science Teaching 52 (6): 847-867

[15] Minetti, A. E. (1995), "Optimum gradient of mountain paths", J Appl Physiol, 79: 1698-1703

[16] Burden, R. L.; and Faires, J. D. (2010), "Numerical Analysis". th $^{\text {th }}$ edition, Cengage Learning

[17] Minetti, A. E.; Moia, C.; Roi, G. S.; Susta, D.; and Ferretti, G. (2002), "Energy cost of walking and running at extreme uphill and downhill slopes." J. Appl. Physiol. 93 (3): 10391046 